\title{
O PROGRAMA ESCOLAS INTERCULTURAIS DE FRONTEIRA (PEIF) COMO POLITICA LINGUÍSTICA
}

Alejandro Lorenzetti

(UEPG)

Cloris Porto Torquato

(UEPG)

\section{RESUMO:}

O Programa Escolas Interculturais de Fronteira (PEIF), parte das políticas linguísticas do Mercosul, fez em 2015 dez anos. Durante esse tempo, numerosas ações foram realizadas e muito se tem escrito sobre elas. Neste artigo, a partir da leitura de documentos oficiais e do confronto com estudos de campo, objetivamos traçar um panorama da sua atualidade e analisar as políticas aí produzidas. Diante do novo contexto político e econômico do Mercosul, em que as ações do programa estão sofrendo cortes e adiamentos, faz-se necessário pensar este momento como uma oportunidade para avaliar o feito, conferir quais dos objetivos iniciais continuam a nortear o PEIF, e reorientar as ações de acordo com as necessidades e problemáticas surgidas durante esta primeira década de andamento. Nesse sentido, acreditamos que o arcabouço teórico e metodológico da visão ampliada de Políticas Linguísticas (SPOLSKY, 2004; Mc CARTY, 2011) resulta esclarecedor para essa tarefa, e o apresentamos aqui como uma via de análise possível. Começamos recordando os pontos principais dos documentos fundadores do PEIF. Em seguida, confrontamos esses pontos com dados preliminares da nossa pesquisa, de cunho etnográfico, produzidos no campo, na região de fronteira São Borja (BR) - Santo Tomé (AR), para finalmente elaborar uma reflexão sobre as continuidades e rupturas com o contexto de surgimento desta proposta de política linguística.

PALAVRAS-CHAVE: Programa Escolas Interculturais de Fronteira; política linguística; fronteira. 


\section{Introdução}

Neste artigo, propomos traçar um panorama da atualidade do Programa de Escolas Interculturais de Fronteira (doravante PEIF) na região de Rio Grande do Sul (RS-BR) e Corrientes (AR), compreendendo que esse Programa envolve uma série de atores e ações em Políticas Linguísticas. Dentre os primeiros, salientamos as vozes dos docentes, protagonistas centrais do PEIF, que acompanhamos e entrevistamos, durante os anos 2014 e 2015, em visitas a quatro escolas de ambos os lados da fronteira gaúcho-correntina.

O trabalho de campo, no qual se inserem as visitas e entrevistas, consta de diários de campo, entrevistas, filmagens e registros escritos, digitais e fotográficos colhidos em sucessivas viagens até São Borja (RS), Santo Tomé (AR) e Paso de los Libres (AR). Nelas, visitamos escolas em cada lado da fronteira, participamos de dois encontros de formação na Província de Corrientes (AR) e entrevistamos os protagonistas com diferentes níveis de responsabilidade. Neste trabalho, mobilizamos uma parte desse material, especialmente algumas entrevistas com docentes de ambos os lados e relatórios (lidos durante a pesquisa de campo e transcritos no diário) produzidos por antigos responsáveis técnicos argentinos.

Ao longo do texto, confrontamos as diferentes vozes de distintos atores: as oficiais, expressas em documentos e artigos, e as dos docentes, mediante entrevistas, gravações e registros escritos obtidos no campo. Procuramos, por meio desse confronto, compreender os processos das políticas linguísticas nesse contexto particular. Esta investigação partilha da visão ampliada de políticas linguísticas (McCARTY, 2011; SPOLSKY, 2004) e procura estudar a interação entre seus diferentes níveis (RICENTO; HORNBERGER, 1996).

Na primeira parte deste trabalho, apresentamos o Programa de Escolas Interculturais de Fronteira e o contexto específico do PEIF na fronteira gaúcho-correntina, ou seja, as "escolas gêmeas" brasileiras, em São Borja, e argentinas, em Santo Tomé, que participam do Programa. Em seguida, retomamos o referencial teórico dos estudos em Políticas Linguísticas em uma visão ampliada. A partir desse referencial, na sequência, apresentamos e analisamos algumas ações de políticas linguísticas que configuram e constituem o PEIF no contexto específico fronteiriço brasileiro-argentino anteriormente nomeado. Por fim, tecemos considerações gerais que buscam contribuir para o debate sobre essas políticas linguísticas. 


\section{Que é o PElF?}

Concebido, inicialmente, como um acordo bilateral entre Argentina e Brasil, em 2005 teve início o então Programa Escolas Interculturais Bilíngues de Fronteira (PEIBF), que hoje forma parte das ações do Mercosul Educativo. No site do Ministério de Educação (MEC) do Brasil, é apresentado assim:

O Projeto Escola Intercultural Bilíngue de Fronteira (PEIBF) tem o intuito de promover o intercâmbio entre professores dos países do Mercosul. [...] O objetivo principal do Projeto Escola Intercultural Bilíngue de Fronteira é a integração de estudantes e professores brasileiros com os alunos e professores dos países vizinhos. O foco é a integração, a quebra de fronteira, além da ampliação das oportunidades do aprendizado da segunda língua.

A metodologia adotada no projeto é a de ensino por projetos de aprendizagem. Os professores, de ambos os países, realizam o planejamento das aulas juntos e determinam em quais partes do projeto os professores realizarão o intercâmbio, pelo menos uma vez por semana. Portanto, o que ocorre no PEIBF não é o ensino de língua estrangeira, mas o ensino em língua estrangeira, criando um ambiente real de bilinguismo para os alunos. (MINISTÉRIO DA EDUCAÇÃO ${ }^{1}$ )

Em 2007, foi apresentado o Modelo de ensino comum de zona de fronteira, a partir do desenvolvimento de um Programa para a educação intercultural, com ênfase no ensino do português e do espanhol (MEC, 2008). Esse modelo procura "permitir, organizar, fomentar a interação entre os agentes educacionais e as comunidades educativas envolvidas, de tal maneira a propiciar o conhecimento do outro e a superação dos entraves ao contato e ao aprendizado (MEC e MECyT, 2008, p. 21).

O hoje chamado PEIF $^{2}$ desenvolve-se em cidades da faixa de fronteira e, em especial, em cidades gêmeas de países que fazem limite com o Brasil. Organiza-se na base de acordos curriculares que buscam propiciar que os professores de escolas parceiras cruzem a fronteira, a cada semana, para dar aulas na sua língua materna. Dessa forma, sem ter como objetivo ensinar sua língua, o professor constituiu-se como modelo vivo da cultura do outro país, não ensinando língua, mas promovendo a intercompreensão e o diálogo intercultural.

Desde aquele começo em 2005 até hoje, o Programa vem sofrendo várias mudanças: do lado brasileiro, algumas escolas deixaram de 
integrá-lo, outras tantas foram inseridas; a assessoria pedagógica mudou de responsáveis ${ }^{3}$; e o Programa mudou de status (deixou de ser projeto para tornar-se programa) para o Governo Federal. Do lado argentino, as autoridades que originalmente o sustentaram já não estão à frente dos ministérios e das secretarias, mudando do âmbito nacional (federal) para o provincial, sendo mais estável o elenco das escolas envolvidas. Todas essas circunstâncias fazem com que o andamento fique cada vez mais nas mãos dos protagonistas locais e que a percepção do espaço fronteiriço trabalhado nas ações seja mais a vivida por eles do que a caracterizada pelos documentos oficiais.

\subsection{As escolas envolvidas no PEIF em São Borja e Santo Tomé.}

O ponto da fronteira onde acontece nossa pesquisa é o localizado entre São Borja - RS e Santo Tomé (Corrientes-AR). As cidades estão ligadas por uma história comum das missões jesuíticas e das guerras guaraníticas e do Paraguai, além de uma constante comunicação comercial e familiar pelo Rio Uruguai, e uma recente intensificação das relações por meio do Mercosul, materializado hoje na chamada "Ponte da Integração", aberta em dezembro 1997. Desde então, a zona é autoproclamada como "coração do Mercosul".

As cidades são consideradas "cidades gêmeas" segundo definição do Ministério da Integração:

Art.1. Serão consideradas cidades gêmeas os municípios cortados pela linha de fronteira, seja essa seca ou fluvial, integrada ou não por obra de infraestrutura, que apresentem grande potencial de integração econômica e cultural, podendo ou não apresentar uma conurbação ou semi-conurbação com uma localidade do país vizinho, assim como manifestações "condensadas" dos problemas característicos da fronteira, que aí adquirem maior densidade, com efeitos diretos sobre o desenvolvimento regional e a cidadania. (MINISTÉRIO DA INTEGRAÇÃO NACIONAL $\left.{ }^{4}, 2014\right)$.

Essa condição de "cidades gêmeas" acarreta um tratamento especial do Governo Federal brasileiro, promovendo tanto a presença militar mais marcada quanto atividades comerciais, culturais e educacionais. É nesse contexto que ingressam no PEIF as escolas brasileiras, com apoio financeiro do Governo. Em 2010, as escolas argentinas ํo 484 e № 554 foram constituídas como parceiras, respectivamente, da Escola Municipal 
de Ensino Fundamental (EMEF) Aparício Mariense e da Escola Municipal de Ensino Fundamental (EMEF) República Argentina. Atualmente, em substituição a essas acima mencionadas, outras duas escolas brasileiras integram essa parceria: a EMEF Vicente Goulart e a EMEF Ubaldo Sorrilha, que constituem nosso lócus de pesquisa. As escolas EMEF Vicente Goulart e a N 554 estão localizadas nas zonas centrais de suas cidades. As duas outras estão em regiões periféricas. As escolas de ambos os lados recebem, como estudantes, membros de populações de baixos recursos financeiros, sendo as escolas argentinas muito mais antigas que as brasileiras.

\section{Políticas Linguísticas}

Como afirma Ricento (2006), o estudo das políticas linguísticas está interessado nos problemas sociais que envolvem a linguagem (p. 11) e no papel da linguagem na produção, no exercício e nos efeitos do poder, bem como no poder nas práticas de linguagem (p. 17). Entendendo que as políticas criam e sustentam diferentes formas de desigualdade (TOLLEFSON, 2006), o estudo das políticas linguísticas busca compreender que relações de poder e formas de desigualdade estão sendo criadas e/ou sustentadas nos encontros/conflitos interculturais e bi/multilíngues.

Seu estudo, por outro lado, pode contribuir para explicitar e confrontar essas desigualdades e assimetrias, uma vez que políticas linguísticas são caracterizadas como "um complexo processo sociocultural: 'modos de interação, negociação e produção humanas mediadas por relações de poder' (Mc CARTY, 2004, p. 72)" (McCARTY, 2011, p. 8). Assim, as relações de poder podem ser - nos processos de interação e negociação sociais - reengendradas e reconfiguradas. Nesse sentido, é preciso observar os diferentes níveis de relações em que são engendradas as relações de poder implicadas nas políticas linguísticas, não se limitando ao estudo das ações do Estado e das instituições sobre os sujeitos.

Partimos, pois, de uma visão ampliada de políticas linguísticas (SPOLSKY, 2004; McCARTY, 2011; JOHNSON, 2013), que se volta para os sujeitos, portanto, para o nível micro das políticas linguísticas, não se restringindo às ações oficiais. $\mathrm{O}$ estudo das políticas linguísticas em nível micro, focalizando os sujeitos, requer que o olhar do pesquisador se desloque dos textos e ações oficiais para os sujeitos, para a escuta atenta de suas vozes e para a observação participante em suas práticas socioverbais, relacionando esse nível micro a aspectos ideológicos, sociais, 
políticos e culturais de níveis médio e macro. Dessa forma, partilhamos a posição segundo a qual o estudo de políticas linguísticas requer "descamar a cebola" (RICENTO; HORNBERGER, 1996), ou seja, a investigação dos múltiplos agentes e níveis de ações políticos. Essa tarefa de descamação precisa ser acompanhada do exercício de estabelecer relações entre esses níveis (McCARTY, 2011).

Partindo dessa perspectiva, um dos focos desta investigação é estudar de que modo os sujeitos se apropriam das políticas linguísticas oficiais, se e como as ressignificam, pois compreende-se que os sujeitos não apenas se submetem às políticas oficiais, mas podem resistir a elas, adequá-las a seus contextos específicos e transformá-las, atribuindo-lhes novos sentidos, distintos daqueles inicialmente propostos oficialmente (SPOLSKY, 2004), reconfigurando as relações de poder e as assimetrias. Assim, políticas linguísticas podem ser compreendidas como ações relativas às línguas (formas, valores, usos, funções), tanto implícitas quanto explícitas, tanto aquelas que procedem dos sujeitos/diferentes atores sociais quanto as oficiais. Como elemento integrante/constituinte das políticas linguísticas e que atravessa esses distintos níveis, estão as ideologias linguísticas.

Ideologias linguísticas dizem respeito às "representações, tanto implícitas quanto explícitas, que constroem o cruzamento entre linguagem e seres humanos no mundo social" e às "ideias sobre linguagem e sobre como a comunicação funciona como processo social" (WOOLARD, 1998, p. 3). São múltiplas, porque são múltiplas as divisões sociais/socioculturais, de modo que há muitos e distintos valores entre diferentes grupos sociais (KROSKITY, 1998). Desse modo, compreendemos que, ao analisarmos os discursos oficiais e os discursos pelos docentes sobre o PEIF nas entrevistas, identificamos ideologias linguísticas que são constituídas pelas políticas linguísticas e as constituem neste/deste Programa.

Sendo assim, este trabalho propõe-se a investigar, inicialmente, as políticas oficiais produzidas nos documentos oficiais que orientam o Programa tanto no lado brasileiro quanto no argentino. Pretende-se, especialmente, investigar as políticas linguísticas constituídas nas ações/práticas/ discursos dos sujeitos no nível micro, que tanto podem corroborar quanto contrariar as políticas oficiais (SPOLSKY, 2004). Esses sujeitos (re) significam de distintos modos, nos seus contextos específicos, as ações/ determinações oficiais, e constroem, em suas ações, políticas linguísticas. 


\section{As políticas linguísticas nas diferentes vozes}

\subsection{As vozes oficiais}

Começamos focalizando os documentos oficiais, como aproximação ao que se pretende atingir e aos resultados que se esperam oficialmente do PEIF. Também é possível observar a percepção oficial que se tem do andamento do PEIF, que será confrontada posteriormente com as vozes dos sujeitos protagonistas docentes, de modo a observarmos como esses sujeitos se apropriam das políticas oficiais. Dentre a escassa produção escrita oficial, escolhemos dois documentos:

Modelo de ensino comum de zona de fronteira, a partir do desenvolvimento de um Programa para a educação intercultural, com ênfase no ensino do português e do espanhol (2008), escrito/assinado pelo Ministério de Educação (MEC) e pelo Ministerio de Educación, Ciencia y Tecnología (MECyT);

Escolas interculturais de fronteira (2014), dossiê escrito para o programa "Salto para o futuro", da TV Escola, ligada ao MEC.

O primeiro documento (bilíngue) instaura oficialmente o PEIBF no Brasil e na Argentina concomitantemente. Sendo bilíngue, parece indicar o esforço de cooperação entre os dois países. Esse documento foi posteriormente reformulado para o Mercosul Educativo, em 2012, mas o núcleo da proposta intercultural permanece sem modificações. Aparece, nele, pela primeira vez, o "Modelo comum para o desenvolvimento do Bilinguismo e da Interculturalidade", e a proposta central é o intercambio de docentes:

El Programa tiene como base el intercambio docente a partir de la disponibilidad de equipos ya formados en ambos países y que actúan en las escuelas involucradas. La unidad inicial de trabajo, por lo tanto, es el par de "escuelas-espejo", que actúan juntas formando una unidad operativa y sumando sus esfuerzos en la construcción de la modalidad de educación intercultural y o bilingüe. Esta forma permite a los docentes de los países involucrados vivenciar ellos mismos, en su actuación y en rutinas semanales, prácticas de bilingüismo y de interculturalidad semejantes a las que quieren construir con los alumnos, en la medida en que se exponen a la vivencia con sus colegas del otro país y con los niños de diferentes grados con los que actúan. (MEC e MECyT, 2008) (grifo nosso) ${ }^{5}$. 
Chama-nos atenção a expressão "escolas-espelho": ao mesmo tempo em que inspira uma imagem ideal, esconde as profundas diferenças tanto entre escolas como entre cidades ao longo de toda a fronteira. Essas unidades iniciais de trabalho já carregam em si inúmeras questões: as culturas escolares brasileiras e argentinas assemelham-se? Em quê? Em que se distinguem? Como essas culturas escolares podem interferir na implementação dessa proposta?

Destacamos, desse trecho, diferentes propósitos. O primeiro, a construção de uma modalidade própria (intercultural e/ou bilíngue), merece um tratamento que excede as possibilidades de um programa, demandando ações nos níveis das políticas sócio-educativas e de gestão do sistema educacional mais amplo, indo além das escolas localmente situadas. Pode-se começar ali, mas não se pode limitar às escolas.

O segundo propósito, vivencial, supõe que a experiência dos docentes possa ser replicada pelos alunos: a convivência com colegas e alunos do/no outro país (da/na outra escola) permitira vivenciar práticas de bilinguismo e interculturalidade, as quais serão posteriormente (re)construídas com os alunos. No entanto, no contexto escolar, os alunos vivenciaram essas práticas apenas com os docentes e no seu próprio país (na sua própria escola), configurando um contexto bastante distinto daqueles dos professores.

O documento indica o que entende por interculturalidade e propõe como devem ser os encaminhamentos metodológicos. Nesse sentido, em função das orientações metodológicas, parece ser um texto voltado, sobretudo, aos docentes.

Embora o documento oficialize o Programa de modo partilhado entre Brasil e Argentina, não estabelece como seria a institucionalização do Programa dentro dos Estados nacionais nem dentro do Mercosul. Define que a formação dos docentes ficará a cargo de cada Estado, no entanto não apresenta diretrizes ou indicações comuns para que os Estados constituam as ações de implementação dessa política de cooperação educacional, linguística e cultural, que pretende instaurar interações interculturais bilíngues no contexto educacional, replicando essa construção para o espaço fronteiriço mais amplo. Nesse sentido, é um documento que parece responder a demandas mais situadas nos contextos escolares e no nível médio (formação dos docentes e regulação de sua prática) do que em âmbito político e institucional mais amplo. No nível macro, configura um marco oficial da cooperação bilateral, mas sem muitos efeitos nas ações políticas oficiais. 
O segundo documento, publicado pela TV Escola, foi escolhido como uma atualização da voz oficial, e nele escrevem professores das universidades ligadas ao Programa. Em sua introdução, assinada por Sturza (2014), são retomados tópicos do documento fundador, tais como o caráter modelar da proposta: "A Escola Intercultural de Fronteira pode ser um modelo de escola, e este deve ser seu caminho..." (p. 5); e a centralidade que o "cruce"" tem: "cruzar, na dinâmica proposta para esse programa, (...) coloca o professor no centro do processo... O 'cruce' é o modo como se operacionaliza a principal ação da Escola Intercultural, baseada na troca de docentes." (STURZA, 2015, p. 5). Quase dez anos depois de iniciado o programa, o documento propõe um roteiro de ação similar ao do documento fundador:

Identificar os desafios para a institucionalização, de fato, do PEIF, e sua respectiva consolidação, passa ainda por acompanhamento pedagógico junto às escolas e por ações de formação continuada dos docentes que contribuam para a definição do modelo, mediante reformulação dos projetos pedagógicos existentes, reflexão sobre o currículo e sobre em que medida o mesmo pode ser compartilhado entre as escolas, de forma a estimular a construção de uma cidadania fronteiriça e uma integração das quais a escola seja um espaço real de promoção e efetivação. (STURZA, 2014, p. 6)

A pergunta a fazer aqui é: por que, até agora, essa institucionalização não se deu ou foi parcial? Além desta, outra pode ser feita: qual é a análise que se faz para garantir que as atividades acompanham as linhas que norteiam o PEIF?

Entendemos que ambos os documentos desconsideram que as perspectivas dos sujeitos sobre seus parceiros do outro lado da fronteira - as ideologias - também integram esse fazer docente e o contexto bem como a cultura escolar. A interação entre o nível micro da escola, o nível médio local (sociedades, histórias, culturas) em que essas escolas estão inseridas e o nível macro (das relações políticas binacionais e do Mercosul) está, do nosso ponto de vista, insuficientemente abordada nesses documentos.

Nesse sentido, o "cruce" insere os docentes no contexto e cultura escolares e na cultura mais ampla do país vizinho, sem discutir a possibilidade de conflitos, apontando a construção da cidadania fronteiriça e a integração das escolas como processo harmônico. Nesse contexto, os usos linguísticos constituiriam-se também harmonicamente, e o bilinguismo e a intercompreensão seriam construídos também de modo harmônico. 
Portanto, esse documento apaga relações de poder e conflitos próprios dos usos linguísticos (Mc CARTY, 2004; 2011), os quais, por sua vez, constituem as políticas linguísticas engendradas nas interações sociais.

Para aproximarmo-nos mais do conhecimento dessa política linguística e educacional, os documentos resultaram a porta de entrada, mas fez-se necessário ouvir os docentes e ver as ações empreendidas por esses sujeitos para se ter uma visão do que efetivamente acontece no campo.

\subsection{0 trabalho de Campo}

Com o intuito de investigar como os sujeitos, nas práticas, construíam políticas linguísticas, e como essas construções dialogavam (ou não) com as orientações dos documentos oficias, realizamos três viagens às cidades de São Borja (BR) e Santo Tomé (AR) - uma em setembro de $2014 \mathrm{e}$ as outras em outubro e novembro de 2015. Permanecemos quinze dias cada vez, visitamos quatro escolas, duas de cada cidade, e realizamos seis entrevistas com as equipes docentes e de gestão que participam do PEIF, com uma média de noventa minutos cada uma. Viajamos com os docentes argentinos e observamos encontros de formação oficiais que foram registrados em vídeos.

Além das gravações em áudio das entrevistas e em vídeo nas formações, produzimos um diário de campo, no qual registramos as diferentes atividades da pesquisa no campo, especialmente a observação de atividades escolares, do movimento cotidiano nas cidades (comercial, trânsito fronteiriço), visitas à biblioteca e ao museu público, registradas por escrito e em fotografias. O diário foi sendo construído a partir das notas que tomamos durante os encontros, da recolha de materiais escritos (flyers, apostilas, material de divulgação, registros escolares históricos), do registro de depoimentos (não gravados) de moradores da região e de documentos digitais, como fotos antigas, teses e dissertações que acessamos nos arquivos públicos. Ao final de cada jornada de trabalho, realizamos sistematicamente descrições detalhadas das atividades e reflexões sobre o observado e sobre os materiais recolhidos, incluindo buscas na internet. Depois de cada viagem, foram organizadas pastas digitais que continham esses documentos e os outros tipos de registros mencionados, constituindo um volumoso arquivo multimedial. Esse arquivo, especialmente o documento em que fizemos os registros, resultou indispensável para "reconstruir o itinerário de ser um estranho a ser um membro conhecedor da comunidade, alguém que agora pode analisar com confiança o 
que aconteceu" (BLOMMAERT; DONG, 2010, p.32). Fundamentalmente, configura-se como registro e análise não somente do que mas também de como vimos, ouvimos e observamos (BLOMMAERT; DONG, 2010); é a memória material do trabalho de campo.

\subsection{0 que vimos e ouvimos - as vozes dos docentes}

Antes de iniciar o trabalho de campo, a informação que recebemos dos participantes da pesquisa a respeito do Programa foi a suspensão dos "cruces". Na primeira viagem que realizamos, os docentes e responsáveis municipais brasileiros informaram que era devido às condições exigidas aos docentes argentinos, referentes a seguros, que resultava onerosa para o governo. Já em 2015, somava-se aos entraves o corte de verbas do MEC, decorrente do atual momento político e econômico, cujos efeitos se sentem nas políticas públicas nos diferentes níveis.

Ao entrar no campo procurando observar o funcionamento atual do Programa, a primeira dificuldade encontrada foi que, apesar de os professores ficarem envolvidos em atividades identificadas com o PEIF, os "cruces", o coração da proposta, não acontecem há muito tempo, o que impossibilitou observar aulas. O último foi realizado em 2012, e, no site do Conselho de Educação da província de Corrientes, lemos:

Las Escuelas de Frontera surgen como propuesta superadora de las conocidas Escuelas Interculturales Bilingües que se desarrollaron como un Programa desde 2005 al 2012 en las Escuelas (...) Basadas en intercambio de docentes, con un costo oneroso imposible de mantener en el tiempo y que produjera su ocaso. Permaneciendo los equipos docentes inactivos a la espera de una decisión política. (CONSEJO DE EDUCACIÓN PCIA.DE CORRIENTES, 2014) (grifo nosso). ${ }^{7}$

Essas "Escuelas de frontera" prometem ser uma nova modalidade para substituir o PEIF na província de Corrientes. Na mesma notícia, aparecia:

El año entrante terminada una capacitación específica proveniente de la Dirección de Educación Intercultural Bilingüe de la Provincia, los docentes impactarán en otras Escuelas Primarias, ampliándose el radio de acción de Escuelas de Frontera. ${ }^{8}$ (CONSEJO DE EDUCACIÓN PCIA.DE CORRIENTES, 2014 $)^{9}$

Desse processo de formação participamos como observadores. Diferentemente, do lado brasileiro da fronteira, o processo de formação docente está orientado ao PEIF. 
As observações registradas em diário de campo e as entrevistas que compõem o estudo apontaram uma desconexão entre autoridades educativas dos dois lados da fronteira. Durante o período observado, não se produziram contatos institucionais, apesar de os responsáveis são-borjenses terem afirmado a intenção de realizar um encontro com as/os docentes. Nesse sentido, vale destacar que, apesar de estarem suspensos os intercâmbios docentes, os entrevistados afirmam nas entrevistas que os laços interpessoais entre os docentes persistem por meio das redes sociais.

Na província de Corrientes, pudemos acompanhar e registrar parte do processo de formação tendente a estabelecer uma nova modalidade, as escuelas de frontera. Sem mais definições, reuniram os docentes das escolas pioneiras do PEIF para ensinar conceitos de interculturalidade, fornecendo materiais sobre o tema e tendo encontros periódicos, além de tarefas on line (Diário de campo). Em entrevistas que realizamos posteriormente aos encontros, os professores afirmaram que os conteúdos não são novos para os docentes e que, pela sua participação anterior no PEIF, nada têm a aprender de novo. Concordamos com alguns dos entrevistados: aquele processo sem rumo aparente tendia à "reciclagem" desses professores e ao abandono do já experimentado em favor de um objetivo ainda não muito claro. A única certeza expressa pelos formadores nos encontros foi a de que os "cruces" já não eram parte das suas tarefas docentes. Enquanto isso, foi possível observar, nas escolas argentinas, que os professores estavam exercendo outro tipo de função, como dar aulas para grupos de alunos com dificuldades ou que desistiram e retornam à escola, esta última ação conhecida como Terminalidad Educativa. Mesmo assim tentam dar um viés de interculturalidade a essas atividades, por exemplo, introduzindo textos em português, como ficou registrado durante a nossa participação numa dessas aulas.

No Rio Grande do Sul, mesmo com o desfinanciamento do PEIF e a ausência de "cruces", estão acontecendo incorporações de outras escolas. A resposta pode estar na quantidade de recursos que podem receber por essa incorporação: o PEIF integra o Programa Mais Educação e o Programa Dinheiro Direto na Escola (PDDE), podendo a escola receber, dependendo da quantidade de alunos, maior verba ${ }^{10}$. Nesse caso, a formação que estão recebendo tem ênfase na aprendizagem da língua espanhola, demanda que os professores tinham frente à pouca comunicação que logravam com os alunos argentinos ${ }^{11}$. Sabido é que, sem os intercâmbios, terão muito menos oportunidade institucional de usar a língua em contexto 
escolar. Aparece aqui uma nova pergunta: por que continuam? Questionados sobre o tema, os docentes brasileiros indicaram que não estão cientes da situação de suspensão permanente dos "cruces" que existem do lado correntino, nem questionaram por que eles não estão cruzando.

Diante dessa realidade, e com o intuito de dar continuidade ao Programa, é que se desenvolvem oficinas de língua espanhola para alunos do primeiro ciclo de ensino fundamental. Uma das escolas realizou essas atividades até parar o financiamento PEIF, enquanto a outra continua incluindo as atividades do PEIF dentro dos outros programas anteriormente citados.

Essas situações são respostas inesperadas e criativas, não sendo as atividades desenvolvidas aquelas projetadas inicialmente para o Programa. Explicitam os distintos modos de apropriação das políticas pelos docentes: se a intercompreensão e o bilinguismo não são construídos em aulas em língua espanhola, como determina o documento oficial, ensina-se essa língua (ensino de língua) para promover acesso aos discursos nela produzidos. Nesse contexto, cabe perguntar: qual é o papel dos docentes na condução do PEIF? Alguém os/as ouve?

\section{As vozes de professoras e professores}

As questões que fecham o tópico anterior podem ser respondidas com algumas reservas. Nos documentos, os docentes são evocados, esperam-se deles respostas, mas, no observado em campo, o que se destaca é a ausência de diálogo entre os protagonistas oficiais e os sujeitos locais.

Existem, por parte dos sujeitos docentes, atitudes diferentes nos dois lados da fronteira, mas, em ambos os casos, existem silêncios carregados de sentidos e vozes que se perdem sem achar respostas nos interlocutores. Do lado argentino, parece persistir uma identificação com a "causa" PEIF, expressa nas palavras saudosas que docentes dedicam aos seus pares e alunos e nas lembranças que ecoam nas suas falas.

-Nos quedamos esperando, esperando, que se solucione y que pudiéramos pasar nuevamente a dar esas clases tan interesantes para nosotros...

-Nosotras vivíamos apasionadas...

-Linda experiencia porque fuimos bien tratados y nosotros también tratamos bien a nuestros colegas. Así que hubo una amistad sincera entre los colegas ¿viste? (Diário de campo $\left.{ }^{12}\right)^{13}$ 
Os docentes valorizam muito a experiência dos "cruces", temem que ela não seja aproveitada por ninguém, e ainda gostariam de retomá-los. Relatam que sofreram um choque cultural e linguístico nas escolas brasileiras, mas assinalam que, como agentes de políticas linguísticas, buscam resolver os problemas de compreensão que se constroem nas interações:

El choque así con las dos lenguas es fuerte. Es fuerte cuando uno va del otro lado, las maestras... yo me enfrento con el grado, todos me hablan em portugués y yo tengo que hacerme entender, los niños no saben hablar mi lengua, yo tengo que encontrar la forma de hacerme entender..." "Ese primer choque fue fuerte, y después fuimos viendo, como acomodarnos" (Entrevista escola argentina $\left.{ }^{14}\right)^{15}$

Coloca-se o risco de não ter com quem dividir a difícil superação do choque inicial no novo contexto da ausência dos "cruces". Sentem a desvalorização de suas experiências, suas ações e sua tarefa docente. Essa situação não é particularmente nova. Já em 2008, no relatório do responsável provincial do Programa, essa dificuldade era explicitada, mas com outro teor:

los docentes están pidiendo a gritos una reconciliación integradora entre su empiria pedagógica y los aportes teóricos que como desafío les coloca el programa (algunos de los cuales llegarán al corazón de las tradiciones pedagógicas instaladas en cada país y generarán obviamente resistencia). Y si estos conocimientos de ser escuela y ser docentes no están instalados en las matrices de abordaje de las propias asesoras pedagógicas, debemos instalarlos desde otras instancias. (Diário de campo $\left.{ }^{16}\right)^{17}$

Hoje existe um elemento adicional: ao serem cancelados os "cruces", os docentes argentinos passaram a se preocupar com sua fonte de trabalho. E a necessidade de serem ouvidos pelas autoridades persiste. Diante da ameaça da ausência da fonte de trabalho, calam, mas frequentemente ocorrem episódios de questionamentos por parte das equipes de gestão escolar, assumindo essa voz apagada pelo medo.

No es lo que nosotros queremos. Nosotros tenemos cierta rebeldía pero también tenemos que aplacarnos porque queremos conservar nuestra fuente de trabajo. No podemos nosotros salir y decir 'no queremos hacer esto, queremos hacer lo otro' pero si ya nos dijeron 'olvídense de los cruces' $[\ldots]$ lo remarcaron bien. El que quiera trabajar trabaja, y el que no ya sabe. Nosotras necesitamos trabajar." (Diário de campo $\left.{ }^{18}\right)^{19}$ 
Suas experiências não são levadas em consideração e as tarefas para as quais foram inicialmente chamadas foram abandonadas em função das mudanças empreendidas no nível macro da política institucional. Diante disso, embora sintam falta dos "cruces" e desejem partilhar e retomar esse fazer, submetem-se às mudanças impostas para garantir o trabalho, corroborando as políticas oficiais.

Do lado brasileiro, observamos que o corpo diretivo e os professores de espanhol são o motor da continuidade do PEIF. Registramos como eles promovem a participação nas atividades oficiais que propõe a universidade supervisora ${ }^{20}$, e também a geração de oficinas de língua espanhola para os alunos, o aprimoramento de salas interculturais com literatura em espanhol e cartazes alusivos ${ }^{21}$, entre outras ações que atribuem ao Programa.

A maioria são atividades distintas daquelas previstas inicialmente no modelo e que mantêm o princípio de voltar-se para a língua e o conhecimento da cultura do outro para interagir com ele. Dessa maneira, os docentes ressignificam as políticas oficiais, apropriam-se delas, transformando-as de acordo com o que julgam ser as necessidades locais. Assim, por exemplo, descrevem o que acontece com o ensino de espanhol nas primeiras séries:

(estão levando) as oficinas com a verba do Mais educação. Funciona como mais uma oficina do Mais Educação. A gente que fala que é do PEIF para não fugir, né?"

Vou te falar uma coisa que é importante: vai ter a Feira do Livro aqui em São Borja e aí a gente vai divulgar esse programa na Feira do Livro (...) Vou levar uma amostra dos trabalhos. É uma forma de divulgar o trabalho e uma forma de eles verem que tem interculturalidade entre os países. Mas eu aqui na escola sempre estou disposta a mostrar a cultura deles para os alunos e vice-versa (Diário de Campo) ${ }^{22}$

Mesmo assim, entre os docentes envolvidos, permanecem as dúvidas. A percepção é que estão participando de um projeto sem perspectivas, enquanto não se resolvam os problemas principais: verbas, salários, calendários dispares, "cruces" alternados e continuidade deles etc., como aparece no seguinte depoimento:

... porque nós no Brasil não ganhamos nada, as professoras de Argentina ganham a bolsa, ali começa aquela... como é que é, ó... aquela, a balança: me doo até por ali, mas não tanto, vou chegar aqui as 7,8 horas da noite por quê?[...] ai vem toda essa problemática junto, mas 
nem se comenta que deixam tudo para fazer no final do ano, e não sei por que. Ali elas enrolam, enrolam, já faz sete anos e a coisa não teve jeito, né?[...] algumas vão se cansando porque não tem muito retorno, não tem retorno"23 (Diário de Campo)

Questiona-se, ao mesmo tempo, a utilidade e as finalidades que perseguem os processos de formação. Percebem a universidade como receptora dos maiores benefícios, já que permite aos acadêmicos realizar pesquisas, mas as professoras não recebem na mesma proporção. Persiste a reclamação por serem ouvidas

Esse questionamento que a gente se faz aqui entre nós, a gente não tem como fazer para eles porque eles também acho que passam por esse processo, eles vão fazer porque para eles como estudantes, como universitários é bom. E eles não vão se questionar por que começa tarde... eu acredito que isso aconteceu na reunião com os coordenadores, não conosco ... (Diário de Campo $)^{24}$

Os docentes brasileiros continuam com incerteza sobre futuros “cruces”, enquanto seus pares sabem que não cruzarão: “... o 'cruce' neste momento não tem como fazer. Nem sabem como está a situação da Argentina, se eles estão... se o governo está..." (Diário de campo ${ }^{24}$ ). Assim, a pergunta sobre as finalidades da formação, mesmo esta sendo estruturada ao redor de uma demanda da equipe docente (a necessidade de compreender os alunos falantes de espanhol), ganha um sentido questionador que deve impulsionar uma reavaliação das ações nesse contexto particular para adaptá-la à nova realidade.

\section{Considerações finais}

Tanto pelo lido e apontado em documentos, como pelo observado em campo, podemos afirmar que o PEIF tem carências desde sua origem. Em primeiro lugar, a maioria das questões que ficaram para se resolver durante o andamento do Programa permaneceram iguais ou apareceram novas questões. Encarou-se uma ampliação do programa sem terem resolvido temas, tais como:

- a remuneração equitativa dos professores: uns recebem por integrar o PEIF; para outros, trata-se de uma carga extra não remunerada. Essa decisão ficou a cargo das diferentes administrações, produzindo um desequilíbrio de expectativas e gerando desconforto entre aqueles que se acham em desvantagem. 
- $\quad$ o financiamento: sem previsão de orçamento, sem um organismo único ou organismos paralelos com idênticas funções, o financiamento depende da vontade das gestões e suas possibilidades. Quando os Governos Federais desaparecem como fornecedores, a proposta fica à deriva.

Muito importante é reconhecer que, nos discursos oficiais, aparece o PEIF como motor de integração regional e intercultural. Entendemos que a escola não pode atender a essa demanda. Acreditamos que a Política precede à Política Linguística, mas parece que o Programa inverte essa relação. Uma verdadeira questão macropolítica, como é um processo de integração regional e internacional, não pode ser uma tarefa para ser desenvolvida, desde o nível micropolítico, pela escola, que se encontra já sobrecarregada de demandas. Também vimos como as ações começaram a desenvolver-se sem que as culturas escolares tenham sido historizadas e/ou problematizadas, o que resultou em diversas dificuldades que hoje persistem. Na mesma linha, o PEIF define-se como um programa multilateral, mas, no território observado, funcionam ações isoladas.

O novo contexto político e econômico dos dois países caracteriza um momento de transição do PEIF e encontra-se em risco a continuidade do Programa com sua proposta de fomentar e formar para o diálogo intercultural. É nesse novo cenário macro que o PEIF se configura como uma política linguística de promoção da intercompreensão e do bilinguismo, mas é ressignificado tanto nas ações oficiais quanto reconfigurado pelos docentes nas suas ações de políticas linguísticas locais, situadas.

Um dos aspectos centrais da construção da política linguística oficial é o apagamento, no documento, de possíveis conflitos e a construção do bilinguismo e da intercompreensão como processo harmônico, desprovido de relações de poder.

No que se refere às políticas constituídas pelos sujeitos, observa-se que os docentes são agentes de políticas linguísticas à medida que, não havendo os "cruces", constroem alternativas para que a língua do país vizinho esteja presente no contexto escolar, seja com a leitura de textos em língua portuguesa na escola argentina, seja com aulas de espanhol na escola brasileira; dessa forma, contrapõem-se à proposta oficial (aulas em língua e não de língua) (SPOSKY, 2004).

Embora mantenham esse esforço nas suas ações, os docentes assinalam o risco de toda a experiência intercultural e pedagógica ser esquecida, 
uma vez que as ações do Programa, em cada um dos países, caminham isoladamente, independentemente do país "parceiro".

\section{THE INTERCULTURAL FRONTIER SCHOOLS PROGRAM (PEIF) AS LANGUAGE POLICY}

\section{ABSTRACT}

The Intercultural Schools at the Frontier Program (PEIF), as part of Mercosur language policies, celebrated ten years in 2015. During this time, numerous actions have taken place and much has been written about them. In this article, based on official documents and field studies, we aimed at presenting an overview of its current situation and analyzing the language policies produced. Given the new political and economic context in which the program's actions are suffering cuts and delays, it is necessary to consider this moment as an opportunity to assess what has been done, check which of the initial objectives continue to guide the PEIF, and re guide the actions according to the needs and problems arising during this first decade of progress. In order to do that, we assume the theoretical and methodological framework of the Language Policies (SPOLSKY, 2004; Mc CARTY, 2011), which seems enlightening for this task, and it is here presented as the basis for the analysis. We begin by recalling the main points of the founders of PEIF. Next, we confront them with preliminary data from our ethnographic research, arising from the field, in the border region São Borja (BR) - Santo Tomé (AR), and finally we offer a reflection on the continuities and disruptions that emerge from this language policy proposal.

KEYWORDS: Intercultural Schools at the Frontier Program (PEIF); language policy; border. 


\section{REFERÊNCIAS}

BLOMMAERT, J.; DONG, J. Ethnographic fieldwork: A beginner's guide, Bristol-Buffalo-Toronto: Multilinguals Matters, 2010.

BORGES, P. Programa Escolas Interculturais de Fronteira: uma proposta pedagógica intercultural. In: TV ESCOLA. Escolas Interculturais de Fronteira. Ano XXIV - Boletim 1 - MAIO 2014. Disponível em < http://cdnbi.tvescola.org.br/ resources/VMSResources/contents/document/publicationsSeries/16251501_14_ EscolasInterculturaisdeFronteira2.pdf > . Acesso em: 10 de novembro de 2015.

KROSKRITY, P. Arizona Tewa Kiva Speech as a Manifestation of a Dominant Language Ideoloy. In: SCHIEFFELIN, B.; KROSKITY; WOOLARD, K. Language Ideologies: Practice and Theory. New York; Oxford: Oxford University Press, 1998. pp. $103-120$.

McCARTY, T. L. Entry into conversation. Introducing Ethnography and Language Policy. In: McCARTY, T. L. (Org.). Ethnography and language policy. New York: Routledge, 2011.

MINISTÉRIO DA EDUCAÇÃO. Escola de Fronteira. Disponível em: < http:// portal.mec.gov.br/escola-de-fronteira/escola-de-fronteira $>$. Acesso em 05 de agosto de 2013.

MINISTERIO DA EDUCAÇÃO; Ministerio de Educación, Ciencia y Tecnología. Modelo de ensino comum de zona de fronteira, a partir do desenvolvimento de um Programa para a educação intercultural, com ênfase no ensino do português e do espanhol. Brasília e Buenos Aires, março de 2008.

RICENTO, Thomas. (Org.). An introduction to Language Policy: theory and method, Malden: Blackwell Publishing, 2006.

; HORNBERGER, N. Unpeeling the Onion: Language Planning and Policy and the ELT Professional. In: TESOL Quarterly. Volume 30, Issue 3, pages 401-427, Autumn 1996.

SPOLSKY, Bernard. Language Policy, Cambridge, Cambridge University Press, 2004.

STURZA, E. Introdução. In: TV ESCOLA. Escolas Interculturais de Fronteira. Ano XXIV - Boletim 1 - MAIO 2014. Disponível em < http://cdnbi. tvescola.org.br/resources/VMSResources/contents/document/publicationsSeries/16251501_14_EscolasInterculturaisdeFronteira2.pdf $>$. Acesso em: 10 de novembro de 2015.

WOOLARD, K. Introduction: Language Ideology as a field of Inquiry. In: 
SCHIEFFELIN, B.; KROSKITY; WOOLARD, K. Language Ideologies: Practice and Theory. New York; Oxford: Oxford University Press, 1998. pp. 3-48.

\section{NOTAS}

${ }^{1}$ Escola de Fronteira Apresentação. Disponível em http://portal.mec.gov.br/escola-de-fronteira/escola-de-fronteira (ultima visita 29 de março 2016)

${ }^{2} \mathrm{O}$ Ministério da Educação registrou a exclusão do conceito de bilinguismo, uma vez compreendida a existência de mais línguas em algumas fronteiras. A partir da Portaria No 798/2012, o programa denominou-se Programa Escolas Interculturais de Fronteira. Disponível em: http://www.abmes.org.br/abmes/public/arquivos/legislacoes/Port-798-2012-06-19.pdf. Acesso em: 05 de agosto de 2013.

${ }^{3}$ No lado brasileiro, até a instituição do PEIF, a assessoria pedagógica esteve a cargo do Instituto (IPOL). Desde 2012, no entanto, essa assessoria tem sido prestada por universidades próximas das cidades e, portanto, das escolas brasileiras que integram o Programa.

${ }^{4}$ MINISTÉRIO DA INTEGRAÇÃO NACIONAL- Portaria No 125, de 21 de Março de 2014

5 "O programa baseia-se no intercâmbio de professores a partir da disponibilidade das equipes já formadas em ambos os países e que atuam nas escolas envolvidas. A unidade inicial de trabalho, portanto, é o par de "escolas-espelho" que atuam em conjunto, formando uma unidade operacional e adicionando os seus esforços na construção da modalidade de educação intercultural e bilíngue. Esta forma permite aos professores dos países envolvidos experimentar, eles mesmos, em sua atuação e em rotinas semanais, práticas de bilinguismo e de interculturalidade semelhantes ao que eles querem construir com os alunos, na medida em que são expostos à experiência com seus colegas de outro país e com as crianças de diferentes classes com as quais atuam.” (MEC e MECyT, 2008)

6 “Cruce (ação e efeito de cruzar") é a palavra em espanhol estabelecida entre os professores envolvidos para denominar o intercâmbio semanal de docentes através da fronteira. Pode ser traduzido como "cruzamento".

7 "As Escolas de fronteira surgem como proposta superadora das conhecidas Escolas Interculturais Bilíngues que se desenvolveram como um Programa desde 2005 até 2012 nas Escolas (...) Com base no intercâmbio de professores, com um custo oneroso insustentável no tempo e que produziu o seu declínio. Permanecendo as equipes docentes inativas à espera de uma decisão política." (Consejo de 
Educación Pcia.de Corrientes, 2014)

${ }^{8} \mathrm{http}$ ://consejoeducacion.corrientes.gob.ar/home/escuelas-de-frontera

9 "No próximo ano, terminada uma formação específica do Departamento de Educação Intercultural Bilíngüe da Província, os professores impactarão em outras escolas de ensino fundamental, ampliando o raio de ação de Escolas de Fronteira." (Consejo de Educación Pcia.de Corrientes, 2014)

${ }^{10}$ PEREIRA ASSIS, J. H. do V. Veias abertas nas fronteiras internacionais do Brasil: percalços na efetivação da educação como um direito universal.International Studies on Law and Education 22jan-abr 2016 CEMOrOc-Feusp / IJI Univ. do Porto

${ }^{11}$ Diário de campo: registro de entrevistas com docentes das escolas argentinas $-2014$.

${ }^{12}$ Extraído da entrevista com professoras de uma das escolas argentinas, em Santo Tomé (AR)

13 "Ficamos esperando, esperando, para ser solucionado e e que pudéssemos cruzar novamente para dar essas aulas tão interessantes para nós ... -Nós viviamos apaixonadas ... -Experiência linda porque fomos bem tratados e nós também tratamos bem aos nossos colegas. Então, houve uma sincera amizade entre os colegas, viu?" (Diário de campo)

${ }^{14}$ Idem.

15 "O choque assim, com as duas línguas é forte. É forte quando se passa do outro lado, os professores ... Eu dou de cara com a série, todos eles me falam em Português e eu tenho que me fazer entender, as crianças nãosabem falar a minha língua, eu tenho que achar uma maneira para me fazer entender ... " " Esse primeiro choque foi forte, e depois fomo vendo, como nos acomodar "(Entrevista Escola Argentina)

${ }^{16}$ Diário de campo 2015. Relatório de supervisão Planeamiento conjunto entre docentes argentinos y brasileños. 2008.

17 “'Os docentes estão clamando por uma reconciliação inclusiva entre sua empíria e pedagógica e os aportes teóricos que o programa como desafio coloca para eles (alguns dos quais alcançarão o coração das tradições pedagógicas instaladas em cada país e, obviamente, gerarão resistência). E se estes conhecimentos sobre ser escola e serem docentes não estão instalados nas matrizes de abordagem das próprias assessoras pedagógicas, devemos instalá-las a partir de outras instâncias." (Diário de campo)

${ }^{18}$ Diário de campo 2014.

${ }^{19}$ Não é o que queremos. Temos certa rebeldia, mas também devemos aplacar- 
-nos, porque queremos preservar a nossa fonte de trabalho. Não podemos sair e dizer 'nós não queremos fazer isto, queremos fazer aquilo', mas já nos disseram 'esqueçam os cruces '[...] sublinharam bem isso. Quem quiser trabalhar trabalha, e quem não já sabe. Nós precisamos trabalhar. "(Diário de Campo)

${ }^{20}$ No caso que nos ocupa a equipe supervisora pertence à Universidade Federal de Santa Maria (UFSM)

${ }^{21}$ Diário de campo 2014

${ }^{22}$ Idem.

${ }^{23}$ Idem 13.

24 Idem 13.

${ }^{25}$ Idem 13.

Recebido em: 16 de janeiro de 2016

Aceito em: 09 de maio de 2016 